\title{
A "Locomotiva do País" sob a direção dos trabalhadores.
}

\section{Fabiana $\mathbf{R}$ de A Junqueira *}

DUARTE, Adriano Luiz. $\mathbf{O}$ direito à cidade: trabalhadores e cidadãos em São Paulo (1942-1953). São Paulo: Alameda, 2018.

Palavras-chave: Trabalhadores; populismo; industrialização.

Keywords: Workers; populismo; industrialization.

A "locomotiva do país" ou a cidade "que não pode parar" foram expressões comuns referentes à cidade de São Paulo, surgidas em fins da Segunda Guerra Mundial, que emergem de forma recorrente na década de 1950, período em que a capital paulista sofreu um acelerado desenvolvimento urbano e industrial. Claro que tais epítetos, presentes, sobretudo, na grande imprensa paulistana da época, estavam longe de retratar a realidade da cidade, uma vez que, ao propalar o suposto progresso, ignoravam as dificílimas condições de vida da maior parte da população do município. Em seu livro $O$ direito à cidade: trabalhadores e cidadãos em São Paulo (1942-1953), Adriano Duarte capta a noção de uma cidade em constante movimento, presente nas frases ufanistas da elite paulistana, porém aponta para o protagonismo das classes populares na disputa pelo acesso à modernidade, acesso esse que parecia negado aos trabalhadores(as) dos diversos bairros periféricos da capital paulista.

O livro apresenta o modo como homens e mulheres lidaram com os inúmeros problemas urbanos no momento de intensa industrialização em São Paulo. Talvez isso, por si só, seria suficiente para tornar-se uma obra de leitura instigante, mas o autor ainda apresenta como, entre as lutas pelo direito ao saneamento básico, ao transporte, à luz elétrica e ao acesso à educação, trabalhadoras e trabalhadores construíram um importante senso de cidadania.

Longe de retratar a cidade como um espaço inerte, Duarte segue o movimento da atual historiografia social do trabalho e observa a multiplicidade de ações da classe trabalhadora não apenas dentro, mas também fora das fábricas, priorizando esse espaço em sua análise. Ao mesmo tempo em que o autor estudou a ação de operários no interior dos sindicatos, analisou as organizações de bairro, algumas delas festivas e esportivas, rompendo a dicotomia entre associação de lazer e

Doutoranda do Programa de Pós-Graduação em História da Universidade Estadual de CampinasUNICAMP. Graduada (2011) e Mestre (2014) em História, pela Universidade Federal de São PauloUNIFESP. E-mail: fabijunqueira8@gmail.com. ORCID: https://orcid.org/0000-0003-3431-6188. 
associação política e retratando que foi exatamente na luta pelo direito à cidade que ocorreu a mediação entre ambas.

Esses são alguns aspectos que tornam a obra de Adriano Duarte, autor de extensa produção no campo da história social do trabalho, uma leitura importante, que nos leva à reflexão sobre as dificuldades que assolaram - e assolam ainda hoje - os moradores das grandes cidades brasileiras; mas, sobretudo, nos faz pensar acerca das diferentes formas de ação criadas em determinado momento histórico pelas classes populares para enfrentar os descasos do poder público.

O autor apresenta uma versão da sua tese de doutorado defendida em 2002, cujo enfoque incidiu sobre o bairro industrial da Mooca. A escolha da Mooca, neste estudo, permitiu-lhe deter-se sobre as conexões do contexto nacional com a singularidade local; ademais, a escolha desse espaço específico - à época o bairro com maior concentração industrial de São Paulo - permitiu ao historiador estudar diferentes associações criadas com a participação, embora não exclusiva, de operários.

O livro está dividido em cinco capítulos que, no seu conjunto, retratam como a disputa pelo espaço urbano, além de possibilitar a forja de uma noção própria de cidadania entre as classes trabalhadoras, serviu para que elas ampliassem seus direitos políticos, civis e sociais, criando novas esferas de participação - e atuação política - como associações de bairro ou clubes recreativos, politizando e tornando públicos muitos aspectos antes privados da sua condição.

O primeiro capítulo é dedicado à ação dos Comitês Populares Democráticos (CDPs), organização criada pelo Partido Comunista após a Segunda Guerra, que se espalharam pelos bairros então periféricos de São Paulo. O autor demonstra com clareza como esses comitês - embora visassem, em um primeiro momento, ampliar os quadros militantes do partido e angariar votos para o PCB, fornecendo informações sobre as demandas da periferia - acabaram extrapolando tais intencionalidades, ganhando certa "vida própria". Duarte aponta que os bairros e seus inúmeros problemas vieram a se tornar o centro das preocupações dos CDPs, os quais foram tomados por demandas dos próprios moradores, servindo como catalizadores e ampliadores de pautas próximas ao cotidiano das classes populares. O clima de denúncia formado no interior dos CDPs sobre as precariedades urbanas nos bairros pobres, somado às difíceis condições impostas pelo Pós-Guerra aos trabalhadores e a algumas ações das elites governantes, em especial, no setor de transporte público, impulsionou uma reação popular em 1947. Nesse ano, um movimento contra as tarifas de ônibus causou incêndio e depredação de veículos. O livro de Adriano Duarte oferece valioso aporte para evidenciar como essa mobilização participa da forja de uma consciência de cidadania e de direitos entre os mais pobres, e revela a importância de organizações à semelhança dos CDPs nesse processo.

O segundo capítulo incide mais detidamente na relação do universo fabril com as reivindicações urbanas. Aqui, o autor desenha um pouco mais o cenário do bairro da Mooca, nas décadas de 1940 e 1950, e demonstra como as fábricas e moradias 
se misturavam nesse espaço, possibilitando uma troca de experiências entre o mundo do trabalho e as organizações de bairro. Duarte aponta que as comissões de fábrica devem tributo, nem sempre reconhecido pela historiografia, aos clubes de futebol, às organizações festivas e às sociedades amigos de bairro, lugares por onde transitavam muitas das ideias discutidas e reivindicadas pelos operários nas indústrias. Da mesma maneira, organizações como os CDPs, tratados no primeiro capítulo, aprenderam a se organizar com as práticas advindas das comissões de fábrica, associações étnicas, religiosas e culturais, em uma grande via de mão-dupla.

Se o segundo capítulo havia tratado sobre o mundo das comissões de fábrica, dos sindicatos, das greves e das conexões desse universo com o bairro, no terceiro capítulo o autor se dedica a apresentar dinâmicas similares no âmbito das Sociedades Amigos de Bairro (SABs) e dos Círculos Operários Católicos.

Outro mérito a ser destacado na obra de Duarte é o fato de o autor revelar o que foram as Sociedades Amigos de Bairro, apesar da escassez de fontes sobre essa forma de organização. Nesse mesmo capítulo, o autor ainda trata da centralidade das questões urbanas nas SABs e das formas de atuação dos moradores do bairro nessas organizações. Havia diferenças claras entre as SABs e os CDPs, sobretudo no modo de encaminhamento das reivindicações. Os Comitês, devido às suas origens e vínculos com o PCB, geralmente promoviam abaixoassinados e petições aos órgãos do poder público municipal ou estadual, enquanto que as SABs recorriam quase sempre à mediação de vereadores, deputados ou ao diretório de algum partido para reivindicar alguma melhoria para o bairro. No entanto, Adriano Duarte retrata como, através dessas duas formas de organização, houve conquistas importantes no tocante às transformações urbanas demandadas pelos populares organizados. A intermediação dos políticos ou dos partidos, buscada pelos moradores que compunham as SABs, não significou, na leitura do autor, uma relação de subordinação dos segundos aos primeiros. Ao contrário, o pesquisador discute algumas interpretações que enxergaram homens e mulheres do período Pós-Guerra como sujeitos apáticos ou apolíticos e demonstra como as associações, como CDPs, as SABs ou até mesmo os Círculos Operários Católicos, abordados mais ao fim do capítulo terceiro, foram espaços de atuação política direta, lutas e conquistas.

O capítulo quatro complementa o anterior e discute as consolidadas - e criticadas, há algum tempo - interpretações sobre o populismo, ainda encontradas em muitos trabalhos acadêmicos, que compreendiam as classes pobres do PósGuerra, como uma grande massa manipulada por políticos carismáticos. O autor escreve sobre a abertura de espaço, durante essa época, para alguns políticos cortejarem os trabalhadores, com ênfase no caso de Adhemar de Barros e Jânio Quadros, em São Paulo. Duarte demonstra que, particularmente o segundo, teve importante atuação nas SABs dos bairros periféricos. No entanto, e este é um ponto importante, o potencial eleitoral tanto de Jânio quanto de Adhemar não era um sinal de cooptação ou subordinação dos mais pobres; ao contrário, a negociação era um componente constante e se eles saíssem vitoriosos no 
processo eleitoral isso se dava porque se dispunham a cortejar e atender às demandas dos bairros e de seus moradores.

Por fim, o último capítulo retrata a Mooca como um bairro plural, no qual os moradores descendentes de diferentes etnias dividiam o mesmo espaço e o mesmo sentimento de exclusão social dos bairros periféricos. Se nos capítulos anteriores o autor destaca as agremiações e as lutas dos moradores pelo direito à cidade, o livro vem a termo retratando os inúmeros conflitos, particularmente entre os descendentes da imigração estrangeira e os novos migrantes, chamados genericamente de "nordestinos", que começaram a chegar em grandes levas à capital paulista, após a década de 1950.

A sequência desses cinco capítulos não deixa dúvida de que $O$ direito à cidade - apropriando essa noção do escopo analítico da obra do geógrafo marxista inglês David Harvey, chamando a atenção dos historiadores para a importância da dimensão espacial como componente fundamental de análise - é uma leitura fundamental para aqueles que desejam compreender as lutas das classes populares nas periferias de São Paulo no Pós-Guerra.

O livro apresenta alguns erros recorrentes de digitação - que certamente serão sanados em uma segunda reimpressão - mas nem por isso a narrativa do autor deixa de ser clara, elaborada a partir de uma pesquisa consistente junto a uma gama variada de fontes. O pesquisador soube utilizar sua experiência em trabalhos anteriores e apresentar um conteúdo que agrada não apenas o público acadêmico, mas todos aqueles interessados nas reivindicações históricas feitas pelos pobres por acesso ao transporte público, a creches, escolas, calçamento, saneamento, entre outras. Certamente, a obra muito tem a acrescentar sobre as classes populares na sua atuação como agentes de sua própria sorte, ou melhor, de sua própria história.

Recebido em 03/08/2019

Aprovado em 23/08/2019 